\title{
A NATUREZA E O PRINCÍPIO DOS REGIMES NA FILOSOFIA DE MONTESQUIEU
}

\author{
Patrícia Carvalho Reis ${ }^{1}$ \\ Universidade Federal de Minas Gerais (UFMG) \\ (iD) https://orcid.org/0000-0003-3322-1507
}

\begin{abstract}
RESUMO:
O presente artigo faz considerações sobre dois conceitos essenciais na filosofia de Montesquieu: a natureza e o princípio dos regimes. Num primeiro momento, demonstramos os tipos de regimes existentes no pensamento de Montesquieu. Como ressaltamos, Montesquieu apresenta uma tipologia de regimes diferente da apresentada por Aristóteles. Uma questão que abordamos corresponde ao fato de que, para Montesquieu, o despotismo é considerado um regime próprio e não, um desvio. Após tratar dessa questão, analisamos o conceito de natureza e princípio dos regimes. O primeiro termo diz respeito aos sujeitos que exercem o poder assim como o modo pelo qual o poder é exercido. Já o segundo termo diz respeito aos sentimentos predominantes dos governados em relação ao regime. Por fim, analisamos a natureza e do princípio de cada regime.
\end{abstract}

PALAVRAS-CHAVE: Montesquieu; Regime político; Natureza e princípio.

\section{THE NATURE AND THE PRINCIPLE OF THE REGIMES IN THE PHILOSOPHY OF MONTESQUIEU}

\begin{abstract}
:
The present article makes considerations on two essential concepts in the philosophy of Montesquieu: the nature and the principle of the regimes. At first, we demonstrate the types of regimes that exist in Montesquieu's thought. As we have pointed out, Montesquieu presents a typology of regimes different from that presented by Aristotle. One question we approach is that, for Montesquieu, despotism is considered to be a regime in its own and not a deviation. After dealing with this question, we analyze the concept of nature and principle of regimes. The first term refers to subjects who exercise power as well as the way in which power is exercised. The second term, however, is related to the predominant sentiments of the governed over the regime. Finally, we analyze the nature and principle of each regime.
\end{abstract}

KEYWORDS: Montesquieu; Political regime; Nature and principle.

\footnotetext{
${ }^{1}$ Doutora em Filosofia pela Universidade Federal de Minas Gerais (UFMG), Minas Gerais - Brasil. Email: patrícia.carvalhoreis@hotmail.com
}

REIS, Patrícia Carvalho. A natureza e o princípio dos regimes na filosofia de Montesquieu. Griot : Revista de Filosofia, Amargosa, Bahia, v.16, n.2, p.371-381, dezembro/2017. 
Logo nos primeiras páginas da obra "Do Espírito das Leis", Montesquieu afirma existir três tipos de regimes: monarquia, república e despotismo. ${ }^{2}$ Assim, o regime despótico, no pensamento de Montesquieu, é um regime ao lado da monarquia e da república.

Diante dessa classificação, percebemos que Montesquieu rompe com o pensamento aristotélico no que diz respeito aos tipos de regimes existentes. Para Aristóteles, existem três regimes: a monarquia, a aristocracia, e o governo constitucional. Aristóteles diz também que o desvio da monarquia é a tirania, o desvio da aristocracia é a oligarquia, e o desvio do governo constitucional é a democracia (ARISTÓTELES, 1985, p. 91, 1279 b). Devemos salientar, assim, que na visão do autor grego, os três últimos governos são considerados desvios dos três primeiros.

Salienta-se ainda que Aristóteles afirma existir três tipos de tirania. De acordo com o estagirita, duas espécies da tirania se aproximam da monarquia pelo fato de esses governos atuarem com respeito à lei. Entretanto, apesar de esses governos agirem conforme à lei e terem o consentimento dos súditos, eles também se identificam com a tirania pelo fato de seus governantes agirem de forma arbitrária. Por fim, há uma terceira espécie de tirania, correspondente à monarquia absoluta. Essa monarquia visa aos interesses particulares dos governantes e não aos interesses comuns dos governados (ARISTÓTELES, 1985, p. 141, 1295 a). Constatamos, assim, que nesse tipo de tirania, o governante não respeita às leis, mas somente aos seus desejos.

Em relação à classificação das tiranias no pensamento de Aristóteles, percebemos que a última espécie mencionada no parágrafo acima é a que mais se aproxima do regime despótico no pensamento de Montesquieu. Percebemos, assim, que os dois autores tratam do regime em que um indivíduo governa de acordo com as suas vontades. Entretanto, esses autores conferem uma posição diferenciada a esse regime. ${ }^{3}$

No pensamento de Aristóteles, a monarquia absoluta, considerada como um tipo de tirania, constitui um desvio do regime monárquico. Por sua vez, para Montesquieu, o regime despótico não constitui um desvio do regime monárquico.

\footnotetext{
${ }^{2}$ Como nos lembra Paul Vernière, a origem da tipologia política remonta ao pensamento grego, pelo menos a Heródoto (VERNIÈRE,1980, p. 319). Outra observação interessante desse intérprete francês concerne ao fato de Montesquieu romper com o critério da classificação do número e se apoiar no seguinte critério na sua classificação dos regimes: a Europa moderna, a Antiguidade, os mundos exóticos. O governo republicano é o passado de Roma e de Atenas, o despotismo é o Oriente, o presente é a Europa monárquica (VERNIÈRE, 1980, p. 320).

3 Raymond Aron destaca a importância do pensamento de Aristóteles nos primeiros livros do "Espírito das Leis", especialmente os livros segundo ao oitavo. Aron diz ainda que esses livros foram escritos antes da viagem de Montesquieu à Inglaterra, numa época em que o filósofo francês se encontrava sob a influência predominante da filosofia política clássica (ARON, 1982, p. 25). Aliás, num breve olhar, percebemos a quantidade de referências, na obra de Montesquieu, a Aristóteles. Vernière diz que Montesquieu possuía algumas versões latinas da obra "A Política" de Aristóteles. Em 1734, Montesquieu compra duas traduções francesas dessa obra de Aristóteles: uma correspondente à tradução feita por Oresme e a outra feita por Regius (VERNIÈRE, 1980, p. 319).
} 
Para o autor francês, como já ressaltado, o regime despótico é um regime próprio da mesma forma que a república e a monarquia. ${ }^{4}$

Nesse sentido, percebemos que o ponto divergente entre esses dois pensadores que merece a nossa atenção refere-se ao fato de o despotismo ser um regime próprio na filosofia de Montesquieu e de ser um desvio do regime monárquico no pensamento de Aristóteles. ${ }^{5}$

Feitas essas considerações, é oportuno averiguar as possíveis causas responsáveis por essa nova classificação proposta por Montesquieu. Além disso, é importante investigar se o fato de Montesquieu considerar o despotismo como um regime faz com que esse modo de governo se torne menos arbitrário.

Ao analisar os motivos pelos quais Montesquieu considerou o despotismo um regime, e não um desvio, é importante destacar que, na sua classificação dos regimes, Montesquieu trata, ao lado do regime monárquico e do regime republicano, do termo despotismo, e não, da tirania.

Tendo em vista essa escolha conceitual, cabe traçar algumas considerações sobre o emprego dos termos tirania e despotismo no pensamento do iluminista francês. Esses termos, algumas vezes, são empregados por Montesquieu sem distinção. Destaca-se a seguinte passagem: “(...) mais um poder legítimo de um monarca do que o poder tirânico de um déspota." (MONTESQUIEU, 1979, p. 249, grifo nosso).

Ao analisar o trecho do final dessa frase: "poder tirânico de um déspota", observa-se que Montesquieu utiliza a palavra "tirânico" para qualificar o poder do déspota. Percebe-se, assim, a grande afinidade entre os termos tirania e despotismo. Nessa situação, Montesquieu utiliza um derivado da palavra tirania para caracterizar o poder do déspota.

Entretanto, não se pode esquecer que o autor francês, ao enfatizar o conceito "despotismo", intenta trabalhar com um novo conceito, diferente da já conhecida tirania. Montesquieu considera o despotismo como um regime à parte e não um desvio dos demais regimes. Assim, se Montesquieu identifica o poder tirânico com a atitude de um déspota, ele também trata de forma diferente esses dois termos.

Nesse sentido, é importante destacar a seguinte passagem em que Montesquieu explica o significado da palavra "tirania" por meio de uma nota-derodapé: "Tomo aqui essa palavra como o desígnio de derrubar o governo estabelecido e, principalmente, a democracia. Esta era a significação que lhe conferiam os gregos e os romanos." (MONTESQUIEU, 1979, p. 208).

Nessa passagem, Montesquieu trata a tirania como um desvio de algum regime, geralmente, a democracia. Nesse momento, observamos como a noção de tirania no pensamento desse autor se distancia do seu conceito de despotismo. Assim, enquanto a tirania dá ênfase ao fim de um regime e a tomada do poder por um tirano, o despotismo não dá destaque ao fim de um regime e ao início de uma forma

\footnotetext{
${ }^{4}$ Ressaltamos que Hannah Arendt, na obra "As origens do totalitarismo", propõe a existência de um novo regime característico de nosso tempo: o totalitarismo.

5 Outro ponto em que Montesquieu se distancia da tradição aristotélica na sua classificação dos regimes consiste na forma pela qual o primeiro autor trata o governo republicano. Para Montesquieu, a democracia e a aristocracia são espécies do regime republicano, e não, gêneros de regimes distintos.
} 
autoritária de governo. Pelo contrário, o despotismo é um regime que se destaca por seu modo autoritário, ele não constitui um desvio ou uma degeneração de um regime; ele é um regime próprio. Em outras palavras, para ele existir, não é preciso que outro regime exista e que ele seja uma consequência desse primeiro regime.

Em outro trecho, Montesquieu diz que há duas espécies de tirania: uma real, que consiste na violência do governo, e outra de opinião, que se faz sentir quando os governantes estabelecem coisas que chocam a maneira de pensar de uma nação (MONTESQUIEU, 1979, p. 265). Nesse momento, Montesquieu utiliza a palavra tirania no sentido de exercício arbitrário do poder. Esse exercício pode ser real quando há violência no governo; e, de opinião, quando os indivíduos ficam escandalizados com certas determinações do governante.

Judith Shklar afirma que a tirania se associava somente com os governantes individuais. A autora acrescenta que Montesquieu estava interessado em sistemas políticos, não somente na personalidade dos príncipes (SHKLAR, 1987, p. 85). Observa-se, assim, que apesar da proximidade dos termos tirania e despotismo, o termo tirania enfatiza aquele que usurpou o poder. Por sua vez, o termo despotismo se identifica primeiramente com um determinado tipo de governo e com o sentimento que esse regime transmite aos súditos. ${ }^{6}$

Seguindo esse pensamento, é oportuno destacar a afirmação de Aron concernente ao fato de que a filosofia política clássica não se preocupava muito com as relações de "superestrutura política" e as "bases sociais". Nesse sentido, Aron afirma que Montesquieu inovou ao combinar a análise dos regimes com a análise das organizações sociais. Por isso, nota-se a opção de Montesquieu em trabalhar com o conceito de despotismo, que, apesar de ter semelhanças com o governo tirânico, também apresenta suas peculiaridades como o enfoque dado à organização social e não somente à figura do governante ${ }^{7}(\mathrm{ARON}, 1982$, p. 27).

Sendo assim, Montesquieu confere ao regime despótico uma posição equivalente ao do regime monárquico e republicano. Diante desse rompimento com a tradição aristotélica, cabe nos questionar as implicações dessa nova posição dada ao regime despótico.

Para realizar tal análise, é oportuno investigar se o fato de Montesquieu considerar o despotismo como um regime dá a possibilidade de tratar o regime despótico como um regime político. Numa interpretação rigorosa dos termos da expressão "regime político", o regime despótico não é um regime político, uma vez que ele se opõe à política. Seguindo esse pensamento, regimes políticos correspondem aos regimes inseridos numa ordem política. Em tal ordem, os cidadãos podem decidir, por eles mesmos ou por meio de seus representantes, ações relacionadas com o interesse de toda a população. Por sua vez, regime não político é o regime em que

\footnotetext{
${ }_{6}$ Destacamos que Rousseau apresenta uma abordagem diferente sobre os conceitos de tirania e despotismo. Para esse autor, o regime despótico é mais arbitrário que o tirânico, uma vez que o tirano é aquele que se intromete, contra às leis, a governar segundo as leis; já o déspota é aquele que se coloca acima das próprias leis (ROUSSEAU, 2005, p. 176).

7Destacamos que Aron considera Montesquieu um dos fundadores da sociologia (ARON, 1982, p. 21). Thomas Pangle discorda desse pensamento. Segundo este intérprete, as noções de "sociedade" e "social" têm um caráter secundário no pensamento montesquiano, uma vez que o iluminista francês se dedica mais aos aspectos políticos de uma sociedade, como a natureza e o princípio de um governo (PANGLE, 1973, p. 44-45).
} 
não há preocupação com o bem coletivo, mas somente com os interesses particulares do governante.

Em nossa interpretação, o fato de Montesquieu ter dado ao regime despótico uma posição similar aos regimes monárquico e republicano não significa que o primeiro tenha alcançado a condição de regime político. Em relação a esse assunto, é interessante destacarmos o seguinte comentário de Simone Goyard-Fabre:

\begin{abstract}
Nas três modalidades governamentais que O Espírito das Leis examina, o despotismo aparece como o modelo do anti-político, e nós podemos desde já pensar que a política não responderá a sua essência a não ser em se construindo como aquilo que lhe fará obstáculo: com efeito, ele nega o sentido dela, ele nega o seu valor, desnatura a sua finalidade visto que no lugar de instituir uma relação entre governantes e governados, ele se destrói na medonha dialética do infinito e do zero: o déspota sendo tudo, os súditos não são nada (GOYARD-FABRE, 1993, p. 282).
\end{abstract}

Após demonstrar e analisar a classificação dos regimes no pensamento de Montesquieu, trataremos das especificidades deles. Para tal tarefa, é importante destacar que o autor francês utiliza de duas ferramentas conceituais: a natureza e o princípio dos regimes.

Montesquieu relata que a natureza desses governos vai ao encontro com a ideia que os homens menos instruídos têm deles (MONTESQUIEU, 1979, p. 31). Percebe-se, dessa forma, que os conceitos de monarquia, república e despotismo não são conceitos de difícil compreensão, pelo contrário, esses termos apresentam um alto grau de concretude. Em outras palavras, as pessoas não precisam ter um conhecimento aprofundado para saberem quem são os governantes de determinado território: o rei, o povo ou um déspota.

Seguindo os passos do pensador francês, observa-se que o governo republicano é aquele em que o povo, como um todo, ou somente uma parcela do povo, possui o poder soberano; a monarquia é aquele em que um só governa, mas de acordo com leis fixas e estabelecidas; ${ }^{8}$ por fim, no governo despótico, uma só pessoa, sem obedecer a leis e regras, realiza tudo por sua vontade e caprichos (MONTESQUIEU, 1979, p. 31). Essas definições correspondem à natureza dos governos.

Observa-se, assim, que a natureza de um regime é o que o faz ser como é, constitui sua estrutura particular. Além desse conceito, Montesquieu também introduz outra ideia relacionada com os regimes: o seu princípio. $O$ princípio de um regime constitui a paixão humana que o movimenta, o seu motor, a sua mola. Os princípios de um governo derivam da natureza dos tipos de governos existentes.

Nesse sentido, é oportuno destacar a seguinte passagem em que Montesquieu define os conceitos de natureza e princípio dos regimes:

Entre a natureza do governo e seu princípio, há esta diferença: sua natureza é o que faz ser como é, e seu princípio é o que o faz agir. A primeira constitui sua estrutura particular e, a segunda, as paixões humanas que o movimentam (MONTESQUIEU, 1979, p. 41).

${ }^{8}$ Ressalta-se que no capítulo sexto do livro segundo do "Espírito das Leis", Montesquieu diz que as leis da monarquia supõem canais médios por onde o poder se manifesta. Os canais mais usuais, também chamados de poderes intermediários, são a nobreza e o clero.

REIS, Patrícia Carvalho. A natureza e o princípio dos regimes na filosofia de Montesquieu. Griot : Revista de Filosofia, Amargosa, Bahia, v.16, n.2, p.371-381, dezembro/2017. 
Vernière nos traz uma interpretação interessante sobre essas ideias:

[...] um regime é uma máquina, uma estrutura material que para um cartesiano evoca roldanas, molas, eixos de transmissão, juntas de Cardam. A natureza desse regime se observa no repouso, e a desmontagem desta estrutura se efetua no repouso. Mas, a máquina para funcionar exige uma mola a que se deu corda. É o que Montesquieu chama em política o princípio de governo. À estática política sucede uma dinâmica (VERNIÈRE, 1980, p. 321).

É interessante mencionar o comentário de Montesquieu em relação a algumas interpretações equivocadas dos princípios dos governos. $O$ autor francês nos diz que há grande diferença entre dizer que determinada modificação da alma é a mola de certo governo e dizer que ela não existe absolutamente nesse governo. Essa ideia pode ser exemplificada quando dizemos que a virtude política não é a mola do governo monárquico. Tal fato, porém, não significa que esse sentimento não exista nas monarquias, mas sim, que a virtude não é o motor desse regime (MONTESQUIEU, 1979, p. 21).

Montesquieu concede uma peculiar importância ao princípio, uma vez que a sua força conduz tudo (MONTESQUIEU, 1979, p. 118). Nesse sentido é oportuno destacar a seguinte passagem de Montesquieu localizada nas primeiras páginas da obra "Do Espírito das Leis":

Examinarei, primeiramente, as relações que as leis possuem com a natureza e com o princípio de cada governo e, como esse princípio possui sobre as leis uma suprema influência, aplicar-me-ei em bem conhecê-lo e, uma vez que consiga estabelecê-lo, dele ver-se-á fluírem as leis (MONTESQUIEU, 1979, p. 28).

Dessa forma, percebemos o quanto é importante a noção de princípio no pensamento de Montesquieu. O princípio corresponde às paixões dos indivíduos. Esse conjunto de paixões humanas é o que vai determinar qual regime estará em vigor, e, por conseguinte, quais leis estarão presentes nesse governo.

Assim, um regime governado pelo povo (a democracia) tem como princípio a virtude. A virtude é a paixão ligada ao patriotismo, ao amor pela igualdade, que, por sua vez, requer aversão à tentativa de acúmulo e gasto com riqueza privada. Percebe-se, portanto, que a igualdade na democracia não se limita apenas à esfera jurídica, à igualdade formal, mas ela é acompanhada da igualdade material que exige a ideia de frugalidade. Deve-se ressaltar ainda que essa igualdade não se confunde com a igualdade extrema.

No início do "Espírito das Leis", Montesquieu escreve uma advertência na qual explica de maneira clara o significado de virtude. Esse esclarecimento é direcionado a algumas pessoas que parecem não ter entendido o verdadeiro significado que Montesquieu deu a esse termo. Assim, Montesquieu afirma que o princípio da república, a virtude, corresponde à virtude política, e não, à virtude moral ou cristã. Essa virtude política, conforme já mencionado, refere-se ao amor à pátria e à igualdade (MONTESQUIEU, 1979, p. 21). Segundo Montesquieu, num regime em que somente uma parcela do povo governa (a aristocracia), a ideia de 
virtude presente nos governos democráticos não é necessária, basta uma virtude menor, ou seja, certa moderação.

É importante frisar que, no momento em que Montesquieu escreveu sua obra, não existiam repúblicas nos moldes das repúblicas antigas. Montesquieu, assim como outros pensadores do século XVIII, argumentava que as repúblicas somente poderiam existir em estados pequenos. Para eles, a república dos antigos parecia estar distante dos tempos modernos.

Na monarquia, observa-se o princípio da honra. Esse governo supõe preeminências, categorias e mesmo uma nobreza de origem (MONTESQUIEU, 1979, p. 45). Devido a isso, o princípio desse governo se caracteriza pela busca da distinção, observa-se uma valorização pelos interesses privados em detrimento dos interesses públicos. Nesse governo, as leis ocupam o lugar das virtudes. Louis Althusser afirma que a honra na monarquia não tem relação com a verdade nem com a moral. Esse princípio da monarquia se distancia das características conhecidas da honra como a franqueza, a obediência, a bondade e a generosidade. Esse autor acrescenta ainda que a honra é o ponto de honra não de um mérito adquirido na luta, mas de uma superioridade recebida por nascimento (ALTHUSSER, 1972, p. 99-102).

Por fim, o princípio do governo despótico é o medo. Como mencionamos, esse sentimento não depende da política para ser exercido: mais do que isso, um regime baseado somente no medo se opõe à política. O medo é uma sensação elementar, instintiva, um sentimento de insegurança que causa impotência e passividade. Jean Goldzink nos elucida o conceito desse sentimento:

Lá onde o medo se torna a paixão mais importante, e a bem dizer, única, a ordem política desaparece na monstruosidade proliferante de uma sociedade dessocializada, de uma totalidade mórbida e uniforme sem outra lei nem regra exceto a ausência de lei e regra que resulta no assenhoramento de todos pelas paixões caprichosas de um só [...] (GOLDZINK, 2001, p. 91).

Como mencionado anteriormente, o regime despótico se opõe à política. Um regime que se guia pelo medo impede que os homens se preocupem com o bem público. Não bastasse isso, o regime despótico também impede que os homens se preocupem com o seu bem-estar individual. Nesse regime, os homens são paralisados pelo medo, eles somente devem obedecer às ordens do governante.

Shklar afirma que o medo no pensamento de Montesquieu é um sentimento involuntário e muito imperioso para ser controlado. Além disso, segundo ela, o princípio do medo no governo despótico é um estado permanente de pressentimento, não uma resposta súbita a uma situação que o faça despertar (SHKLAR, 1987, p. 84).

Dessa forma, o medo no despotismo corresponde a um sentimento constante nas pessoas. Ele ocorre porque os súditos podem ser penalizados por situações que não podem prever. Qualquer ato pode ter como consequência uma punição; não somente um ato, mas também a omissão de certa conduta pode dar ensejo a uma penalidade. Nesse regime, o governante ocupa o lugar da pessoa que ameaça. Percebe-se, assim, que, nesse regime, o déspota faz o que lhe convém e os cidadãos 
não sentem segurança. De modo oposto, nos regimes moderados, o sentimento do medo é despertado em situações específicas, o medo não está sempre presente.

Constatamos, portanto, que o medo é a paixão que move o regime despótico. Em decorrência disso, percebemos o quanto esse sentimento é poderoso. Ele não é sentido somente em determinadas ocasiões nem é uma reação súbita dos governados em relação a determinados atos do governante. O medo sempre está presente no íntimo dos súditos, ele parece se integrar à personalidade deles.

Como consequência, verifica-se, nos Estados despóticos, a presença da extrema uniformidade. Os súditos são iguais, o medo permite somente uma forma de manifestação: aquela em que há a obediência cega. Assim, nesses Estados, o homem é a criatura que obedece a outra que manda; o homem se reduz a um ser obediente. Bertrand Binoche faz os seguintes comentários sobre os princípios dos regimes:

A virtude e a honra, de qualquer maneira como nós as entendemos, são paixões sofisticadas e positivas no sentido em que elas obrigam o indivíduo a se afirmar em vista de um objetivo socialmente valorizado; é porque elas exigem práticas pedagógicas de interiorização. $\mathrm{O}$ medo, ao contrário, é a paixão bruta e negativa de um regime cuja repressão define exaustivamente o modo de exercício (BINOCHE, 1998, p. 130).

Percebemos, assim, que o medo faz com que as pessoas se afastem umas das outras. Ele se opõe ao comportamento social. Por outro lado, a virtude e a honra são paixões com objetivos sociais. Ademais, para que virtude e a honra sejam vivenciadas é preciso que as pessoas desde crianças aprendam a sentir essas paixões. Por outro lado, o medo é instintivo, ele não precisa ser ensinado, ele nasce espontaneamente.

Diante do exposto, percebemos que o princípio é aquilo que move o governo. O princípio é que vai determinar o tipo de regime de uma país. Como já mencionado, a virtude pode não ser o único sentimento presente nas repúblicas; entretanto, se ela não existir nesse governo, a república cairá, o mesmo ocorre com a monarquia sem a honra e o despotismo sem o medo. Nesse sentido, Althusser comenta que a natureza é um conceito de direito constitucional, é uma forma jurídica. Já o princípio relacionase com algo concreto, ele é o ponto de encontro da natureza do governo e da vida real dos homens (ALTHUSSER, 1972, p. 62).

Posteriormente, Montesquieu deixará a repartição tripartite dos regimes e tratará apenas de duas categorias de regimes: os moderados e o despótico. Assim, apesar de a república e a monarquia apresentarem diferentes características, elas possuem algo em comum: não existe nesses regimes o mando arbitrário, a ausência das leis. Esse desvio de interpretação é demonstrado na seguinte passagem de Montesquieu:

O inconveniente não surge quando o Estado passa de um governo moderado a outro governo moderado, como da república à monarquia, ou da monarquia à república, mas quando cai e se precipita do governo moderado ao despotismo (MONTESQUIEU, 1979, p. 117).

Binoche acrescenta que Montesquieu recusa a questão tradicional do melhor governo e a substitui por aquela do pior governo (MONTESQUIEU, 1998, p. 24). De fato, ao interpretar as obras de Montesquieu, pode-se observar que ele não tem 
intenções de pesquisar o governo ideal. Como veremos no terceiro capítulo, Montesquieu tem uma grande admiração pelo governo inglês, mas esse regime não constitui o interesse primordial do seu trabalho. A obra de Montesquieu é marcada pela temática do combate ao regime despótico. $O$ governo inglês, assim como outros governos moderados, constitui alternativa ao despotismo. Pode-se dizer que o governo da Inglaterra é o que mais se afasta do regime despótico. É por isso que Montesquieu dedica uma atenção especial ao governo desse país.

Para Montesquieu, a república e a monarquia estão bem caracterizadas na categoria dos governos moderados. $O$ filósofo francês não optou pela análise referente à questão de a república convir mais do que a monarquia, muito menos se interessou em avaliar se a democracia seria melhor do que a aristocracia. Montesquieu não defende a existência de um melhor tipo de governo, uma vez que ele acredita no fato de que cada país apresenta suas particularidades e, por isso, um tipo de governo pode não ser bom para todas as nações. Entretanto, Montesquieu se esforçava em combater o despotismo, o pior regime, pois esse regime não poderia ser bom em nenhum lugar do planeta. 


\section{Referências bibliográficas}

ALTHUSSER, Louis. Montesquieu a Política e a História. Tradução de Luz Cary e Luisa Costa, 2 ed. Lisboa: Editorial Presença Portugal, 1977.

ARISTÓTELES. Política. Tradução de Mário da Gama Kury. Brasília: Editora Universidade de Brasília, 1985. Original grego.

ARON, Raymond. As etapas do pensamento sociológico. 1.ed São Paulo: Martins Fontes, 1982.

BINOCHE, Bertrand. Introduction à De l'esprit de lois de Montesquieu. Paris: Presses Universitaires de France, 1998.

Despotisme. Dictionnaire électronique Montesquieu, 2008. Disponível em: http://dictionnaire-montesquieu.ens-lsh.fr/index.php?id=395 . Acesso em: 14/08/2008.

BOBBIO, Norberto; MATTEUCCI, Nicola; PASQUINO, Gianfranco. Dicionário de Política. 3. ed. Brasília: Editora Universidade de Brasília, 1983. 2v.

CHEVALLIER, Jean-Jacques. História do pensamento político Tomo 2. Rio de Janeiro: Editora Zahar, 1983.

DÉDÉYAN, Charles. Montesquieu ou l'alibi persan. Paris: Sedes, 1988.

DEDIEU, Joseph. As idéias políticas e morais de Montesquieu. In: QUIRINO, Célia Galvão; SOUZA, Maria Tereza Sadek R. de. O pensamento político clássico: Maquiavel, Hobbes, Locke, Montesquieu, Rousseau. São Paulo: T.A. Queiroz, 1980, v.2, capítulo 13, p.249-289.

DURKHEIM, Emile. Como Montesquieu classifica as sociedades por tipos e por espécies. In: QUIRINO, Célia Galvão; SOUZA, Maria Tereza Sadek R. de. O pensamento político clássico: Maquiavel, Hobbes, Locke, Montesquieu, Rousseau. São Paulo: T.A. Queiroz, 1980, v.2, capítulo 12, p. 237-248.

EHRARD, Jean. Politique de Montesquieu. Paris: Armand Colin, 1965.

GOYARD-FABRE, Simone. Montesquieu: la Nature, les Lois, la Liberté. Paris: Presses Universitaire de France, 1993.

GOLDZINK, Jean. Montesquieu et les passions. Paris: Presses Universitaires de France, 2001.

GROETHYSEN, Bernard. Montesquieu- a razão construtiva. In: QUIRINO, Célia Galvão; SOUZA, Maria Tereza Sadek R. de. $O$ pensamento político clássico: Maquiavel, Hobbes, Locke, Montesquieu, Rousseau. São Paulo: T.A. Queiroz, 1980, v.2, capítulo 14, p. 291-304.

MONTESQUIEU, Charles Louis de Secondat. Do Espírito das Leis. Tradução de Fernando Henrique Cardoso e Leôncio Martins Rodrigues. São Paulo: Abril Cultural, 1979.

PANGLE, Thomas. Montesquieu's Philosophy of Liberalism. Chicago: The University of Chicago Press, 1973.

ROUSSEAU, Jean Jacques. Do contrato social. São Paulo: Martins Fontes, 2005.

SHKLAR, Judith N. Montesquieu. Oxford: Oxford University Press, 1987.

TROPER, Michel. Séparation des pouvoirs. Dictionnaire électronique Montesquieu, 2008. Disponível em: http://dictionnaire-montesquieu.ens-lsh.fr/index.php?id=286 . Acesso em 10/02/2010. 
VERNIÈRE, Paul. Dois planos e duas leituras. In: QUIRINO, Célia Galvão; SOUZA, Maria Tereza Sadek R. de. O pensamento político clássico: Maquiavel, Hobbes, Locke, Montesquieu, Rousseau. São Paulo: T.A. Queiroz, 1980, v.2, capítulo 15, p. 305-350.

WOLFF, Francis. Aristóteles e a Política. 19.ed. São Paulo: Discurso Editorial, 1999.

Autor(a) para correspondência: Patrícia Carvalho Reis, Universidade Federal de Minas Gerais, Faculdade de Filosofia e Ciências Humana, Avenida Antônio Carlos, 6627 - Pampulha, CEP 31270 901, Belo Horizonte - MG, Brasil. patrícia.carvalhoreis@hotmail.com 